\title{
The Ameliorative Effect of Angelica acutiloba Ameliorates Through the NO / iNOS Pathway in Rats with Systemic Allergy
}

\author{
Min-Seok Cho ${ }^{1, *}$, Hae-Woong Park ${ }^{1, *}$, Gil-Hyun Lee ${ }^{2, * *}$, Hae-Gyung Yoon ${ }^{3, * *}$, \\ Kyung-Mo Oh ${ }^{4, * *}$, Seok-Cheol Choi ${ }^{1, * *}$ and Kyung-Yae Hyun ${ }^{2, \dagger, * *}$ \\ ${ }^{1}$ Department of Clinical Laboratory Science, Catholic University of Pusan, Busan 4625, Korea \\ ${ }^{2}$ Department of Clinical Laboratory Science, Dong-Eui University, Busan 47340, Korea \\ ${ }^{3}$ Division of Basic Sciences, Dong-eui University, Busan 47340, Korea \\ ${ }^{4}$ Department of Sports Leisure, Busan Kyungsang College, Busan 47583, Korea
}

\begin{abstract}
This study was undertaken to investigate the therapeutic effect of Angelica acutiloba on allergic dermatitis, which Angelica acutiloba is traditionally known to have antiinflammatory effects. Sprague-Dawley (SD) rats were divided into five groups: normal control group, experimental allergic dermatitis group (vehicle group), low dose of Angelica acutiloba extract (low-dose group), high dose of Angelica acutiloba extract (high-dose group), and antihistamine treated group with experimental dermatitis (antihistamine group). Total leukocyte, neutrophil, lymphocyte, monocyte and eosinophil counts were significantly higher in the vehicle group than in the control group, but these variables were significantly lower in the low- and high-dose groups than in the vehicle group. The platelet/lymphocyte ratio in the red blood cell index was significantly lower in the low- and high-dose groups than in the vehicle group. Low and high doses of the Angelica acutiloba extract did not have toxic effects on liver and kidney. Serum NO, iNOS and levels were highest in the vehicle group but significantly lower in the low- and high-dose groups, especially in the high-dose group. The results of this study suggested that the Angelica acutiloba extract had the effect of alleviating or treating the experimental allergic dermatitis, and it was concluded that the high dose was more effective.
\end{abstract}

Key Words: Experimental allergic dermatitis, Angelica acutiloba, Total white blood cell, NO, iNOS

\section{INTRODUCTION}

In developing countries, it is estimated that the number of asthmatic patients is about 300 million people, and about 400 million people suffer from allergic rhinitis (Pawankar et al., 2009). In the United States, allergic diseases are the sixth most common chronic disease, affecting $17 \%$ of the population. The resulting cost of health care spending amounts to about $\$ 18$ billion annually. In Korea, the diagnosis of allergic reactions, including atopic dermatitis in elementary school students has increased from $13.7 \%$ in 1995 to $29.2 \%$ in 2005 (Hong, 2007). According to the National Health Insurance Corporation data, the number of patients with atopic dermatitis from 759 in 2007 to 1,264 in 2011, the annual average rate has increased by $13.6 \%$, and the proportion of serious patients is also increasing. Atopic dermatitis is a chronic recurrent eczema characterized by lancet fever that

Received: February 28, 2019 / Revised: March 15, 2019 / Accepted: March 18, 2019

*Graduate student, ${ }^{* *}$ Professor.

†Corresponding author: Kyung-Yae Hyun. Department of Clinical Laboratory Science, Dong-Eui University, Busan 47340, Korea. Tel: +82-51-890-2683, Fax: +82-51-890-2622, e-mail: kyhyun@deu.ac.kr

(C)The Korean Society for Biomedical Laboratory Sciences. All rights reserved.

(c) This is an Open Access article distributed under the terms of the Creative Commons Attribution Non-Commercial License (http://creativecommons.org/licenses/by-nc/3.0/) which permits unrestricted non-commercial use, distribution, and reproduction in any medium, provided the original work is properly cited. 
is often difficult to cure. The clinical manifestations of atopic dermatitis are very diverse, and the severity of the disease also varies. In recent years, the number of patients with severe symptoms is increasing. In addition, if atopic dermatitis is not actively treated early, the so-called 'atopy march' appears, which progresses to asthma and rhinitis. So far, there is no way to completely cure atopic dermatitis. Treatment of patients with atopic dermatitis includes basic methods for protecting the skin, treatment for dermatitis, identification and elimination of inflammatory factors, etc. (Krakowski et al., 2008). The treatment should be based on the age, sex, cost, location and severity of the patient, and personalization of each patient to identify the deterioration factors and how to deal with them. Since atopic dermatitis does not have a fundamental cure, its goal should be to alleviate symptoms, prevent early treatment, prevent lesion worsening, and prevent recurrence as far as possible. Atopic dermatitis is the most common treatment method currently available. Steroids can cause side effects such as skin atrophy, telangiectasia, hypopigmentation, steroid acne, increased hair growth, rosacealike eruption, inhibition of hypothalamic-pituary-adrenal axis disturbance, increased risk of glaucoma and cataract, and Cushing's syndrome (Kim and Cho, 2014). Calcineurin inhibitors may induce kidney dysfunction, elevated blood pressure, headache, hyperlipemia, vomiting, abrasion, gum enlargement, increased blood sugar, increased risk of infection, hand shaking, diarrhea, anorexia, stomach dysfunction, anemia, leukopenia, and thrombocytopenia (Fleisher, 1999; Sidbury and Hanifin, 2000; Haper et al., 2001; Kang et al., 2001; Murphy and Atherton, 2001). Phototherapy is a timeconsuming procedure that requires frequent visits to hospitals. Nonsteroidal agents exert cytopenia, gastrointestinal disorders, and hematopoietic function impairment (Sidbury and Hanifin, 2000). Immune response modifiers have disadvantages, such as high recurrence rate, fever, body aches, headache and eosinophilia after treatment of atopic dermatitis. Therefore, we have designed this study to find a physiologically active substance which exerts the effect of relieving or treating and has little side effects on systemic allergic symptoms. In this study, we examined the effect of Angelica acutiloba in SD rats with experimental allergic reactions.

\section{MATERIALS AND METHODS}

\section{Animals and grouping}

5 weeks-aged SD male rats were purchased (Dong Joo Medilab., Busan, Korea) and subjected to animal adaptation for 1 week before being used in the experiment. The temperature was maintained at $24 \pm 2{ }^{\circ} \mathrm{C}$ and the humidity was maintained at $40 \sim 60 \%$. Sterilized drinking water and solid feed were freely available. Rats were classified into five groups. The control group $(n=10)$ did not undergo any treatment and the other four groups were administered with OVA - $40 \mu \mathrm{g}$ and $\mathrm{AL}(\mathrm{OH}) 3 \sim 5 \mathrm{mg}$ three times a week by intraperitoneal injection to induce a delayed hypersensitivity reaction. The vehicle group that atopic dermatitis was induced but not any treated (Vehicle group, $\mathrm{n}=10$ ). A dose of $12.5 \mathrm{mg} / \mathrm{kg}$ weight of Angelica acutiloba extract was orally administered (Lowdose group, $\mathrm{n}=10$ ), a dose of $50 \mathrm{mg} / \mathrm{kg}$ weight of Angelica acutiloba extract was orally administered (High dose group, $\mathrm{n}=10$ ), and $0.41 \mathrm{mg} / \mathrm{kg}$ weight of CLARITYNE TAB antihistamine was orally administered (Antihistamine group, $\mathrm{n}=10)$.

This study was accepted by the Animal Ethic Committee of the Catholic University of Pusan.

\section{Experimental allergic reaction and dermatitis}

After inducing the delayed hypersensitivity reaction, the experimental groups were removed $2 \times 2 \mathrm{~cm}$ area of the dorsal hair and were induced dermatitis on the local area using a brush with 3 25 mg of ovalbumin (OVA) and $150 \mu \mathrm{g}$ of $\mathrm{AL}(\mathrm{OH})$. After induction of delayed hypersensitivity reaction, $1.5 \mathrm{cc}$ of $0.85 \%$ saline was orally administered in the vehicle group. Once every two days from one week after patch sensitization, a dose of $12.5 \mathrm{mg} / \mathrm{kg}$ or $50 \mathrm{mg} / \mathrm{kg}$ of the Angelica acutiloba extract were orally given in the low- and high-dose-groups (Fig. 1).

\section{Preparation of Angelica acutiloba extract}

$100 \mathrm{~g}$ of Angelica acutiloba were extracted into 1 liter of $80 \%$ ethanol and the extract was prepared. The ethanol was evaporated at $65^{\circ} \mathrm{C}$ for 5 days, and distilled water was added to the evaporated amount. After filtration using $3 \mathrm{mM}$ filter 
paper, the filtered extract was used. It was confirmed that $0.05 \mathrm{~g}$ of Angelica acutiloba was contained per $1 \mathrm{~mL}$ of the extract. The extracts were measured by spectrophotometer at $600 \mathrm{~nm}$ and showed a concentration of 0.430 .

\section{Antioxidant activity analysis of Angelica acutiloba extract}

DPPH (1,1-diphenyl-2-picryl hydrazyl) was tested to evaluate the antioxidant activity of Angelica acutiloba extract. Antioxidant activity means the ability of certain substances to remove free radicals. This experiment is based on the property that DPPH hydrazyl absorbs hydrogen atoms easily because it contains unstable nitrogen atoms, and thus reacts with antioxidative substances and loses inherent colorability by accepting hydrogen atoms. The degree of decrease of radicals using DPPH was measured by a spectrophotometer, and indirectly, the antioxidant activity of the extract was measured. When the radical was reduced to an antioxidant, it lost its original purple color and turned yellow. The analysis process is as follows: The DPPH solution was prepared by mixing $0.08 \mathrm{~g}$ of DPPH and $1 \mathrm{~L}$ of ethanol in a light-dark room. The prepared DPPH solution was stored at $-20^{\circ} \mathrm{C}$. Then, extracts for antioxidant activity evaluation were prepared by concentration. Then, extracts for antioxidant activity evaluation were prepared by concentration. The extract was prepared at six concentrations of $1,000 \mu \mathrm{g} / \mathrm{mL}, 500 \mu \mathrm{g} / \mathrm{mL}$, $250 \mu \mathrm{g} / \mathrm{mL}, 125 \mu \mathrm{g} / \mathrm{mL}, 62.5 \mu \mathrm{g} / \mathrm{mL}$ and $31.25 \mu \mathrm{g} / \mathrm{mL} .1 \mathrm{~mL}$ of DPPH solution was added to $1 \mathrm{~mL}$ of this extract (control: $99.5 \%$ ethanol), shaken for 10 seconds using a vortex mixer, and incubated at $37^{\circ} \mathrm{C}$ for 30 minutes. As a positive control, L-ascorbic acid was prepared at 6 concentrations as in the above extract, and $1 \mathrm{~mL}$ of DPPH solution was added to prepare a control solution. Then, the absorbance was measured at $517 \mathrm{~nm}$ using an X-mark micro spectrophotometer reader. The antioxidant activity of the Angelica acutiloba extract and the positive control was compared with the absorbance of the control. The inhibition rate of DPPH activity was determined according to the following equation, assuming that the absorbance of the control group without the extract Angelica acutiloba (control group) was abs (control). And it is shown in Fig. 2.

Inhibition rate $(\%)=$ abs (control) - abs (sample)/ abs (control) $\times 100$

Fig. 3 is a graph showing the results of the antioxidant activity evaluation test of the Angelica acutiloba extract. As shown in Fig. 1, the antioxidant activity of L-ascorbic acid, a positive control drug, $93.93 \%$ was at a concentration of $1,000 \mu \mathrm{g} / \mathrm{mL}, 91.37 \%$ was at a concentration of $500 \mu \mathrm{g} / \mathrm{mL}$,

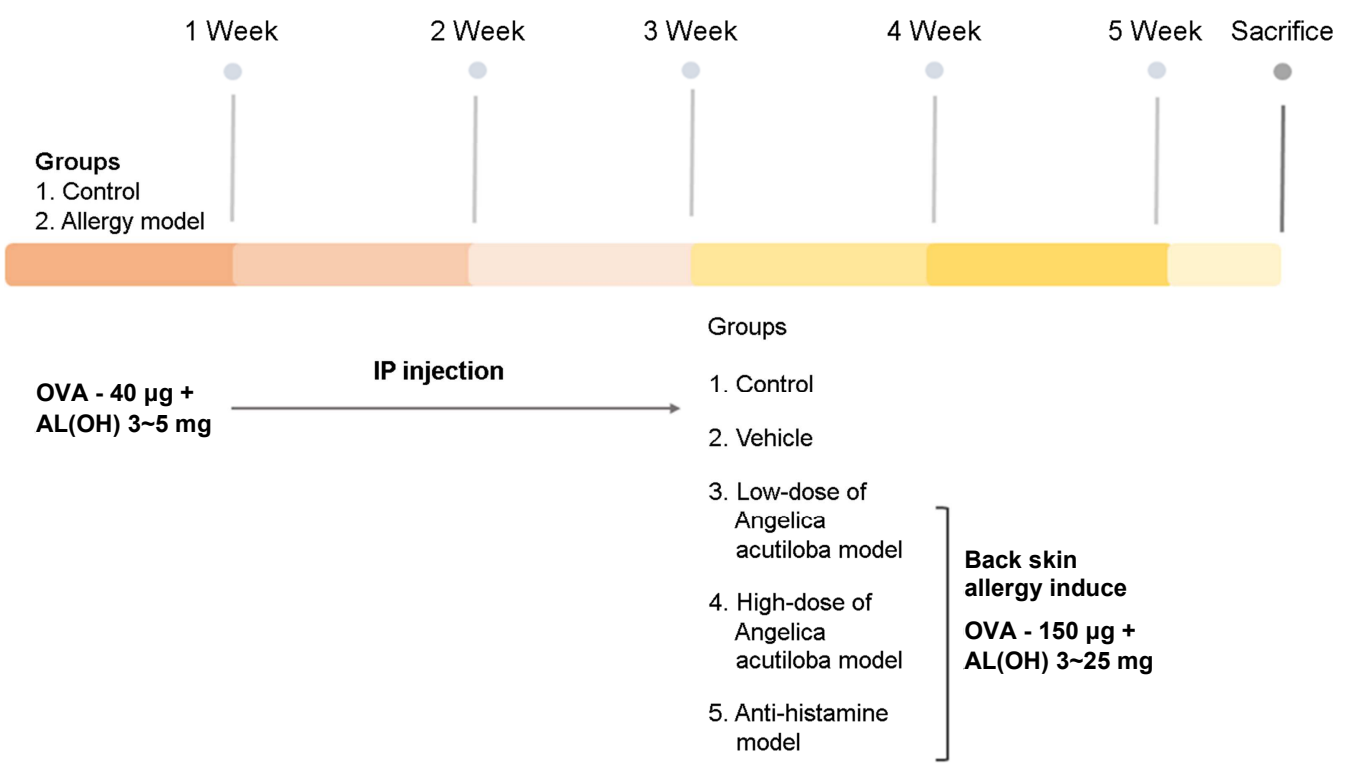

Fig. 1. Experimental schedule. 
and $90.73 \%$ was at a concentration of $250 \mu \mathrm{g} / \mathrm{mL}, 89.46 \%$ was at a concentration of $125 \mu \mathrm{g} / \mathrm{mL}, 88.77 \%$ was at a concentration of $62.50 \mu \mathrm{g} / \mathrm{mL}$, and $84.35 \%$ was at a concentration of $31.25 \mu \mathrm{g} / \mathrm{mL}$. The antioxidant activity of the Angelica acutiloba extract was $71.25 \%$ at a concentration of $1,000 \mu \mathrm{g} /$ $\mathrm{mL}, 66.13 \%$ at a concentration of $500 \mu \mathrm{g} / \mathrm{mL}, 45.05 \%$ at a concentration of $250 \mu \mathrm{g} / \mathrm{mL}, 11.50 \%$ at a concentration of $125 \mu \mathrm{g} / \mathrm{mL} .0 .96 \%$ at a concentration of $62.50 \mu \mathrm{g} / \mathrm{mL}$, and $0.00 \%$ at a concentration of $31.25 \mu \mathrm{g} / \mathrm{mL}$.

As shown in Fig. 3, DPPH reacted with the Angelica acutiloba extract to lose its original purple color and turned yellow as the increased concentrations of the Angelica acutiloba extract. Therefore, as shown in Fig. 3 and Fig. 4, the Angelica acutiloba extract exhibited antioxidative activity in a concentration-dependent manner, and about $50 \%$ of activity was observed at $250 \mu \mathrm{g} / \mathrm{mL}$.

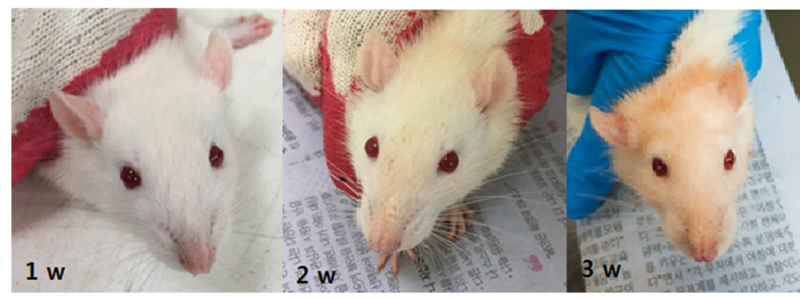

Fig. 2. Change of face color of rats according to experimental allergic reaction. $1 \mathrm{w}, 1$ week after induction of allergic reaction; $2 \mathrm{w}, 2$ week after induction of allergic reaction; $3 \mathrm{w}, 3$ week after induction of allergic reaction.

\section{Sacrifice and sampling}

All rats were fasted for 24 hours before sacrifice, were anesthetized by ether and fixed on the rat operating table (Dong Sew Science, Korea). The heart was exposed with upper abdominal incision and $6 \mathrm{~mL}$ of blood was collected directly from the heart. $1.0 \mathrm{~mL}$ of the blood was infused into EDTA bottle for measuring CBC \& diff-count, $2 \mathrm{~mL}$ blood was used for analysis of liver and renal function markers, and the remainder nitric oxide (NO) concentrations.

For histopathological examination of skin tissue, hair was removed with a razor, and skin tissue was cut into $2 \mathrm{~cm} \times$ $2 \mathrm{~cm}$ size. Half of the cut tissues were frozen at -70 for

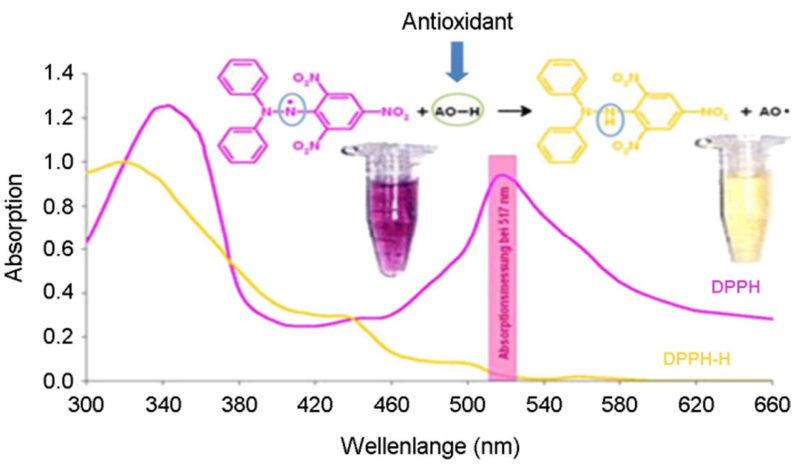

Fig. 4. The reaction of DPPH with the Angelica acutiloba extract. DPPH reacted with the Angelica acutiloba extract to lose its original purple color and turned yellow as the increased concentrations of the Angelica acutiloba extracts.

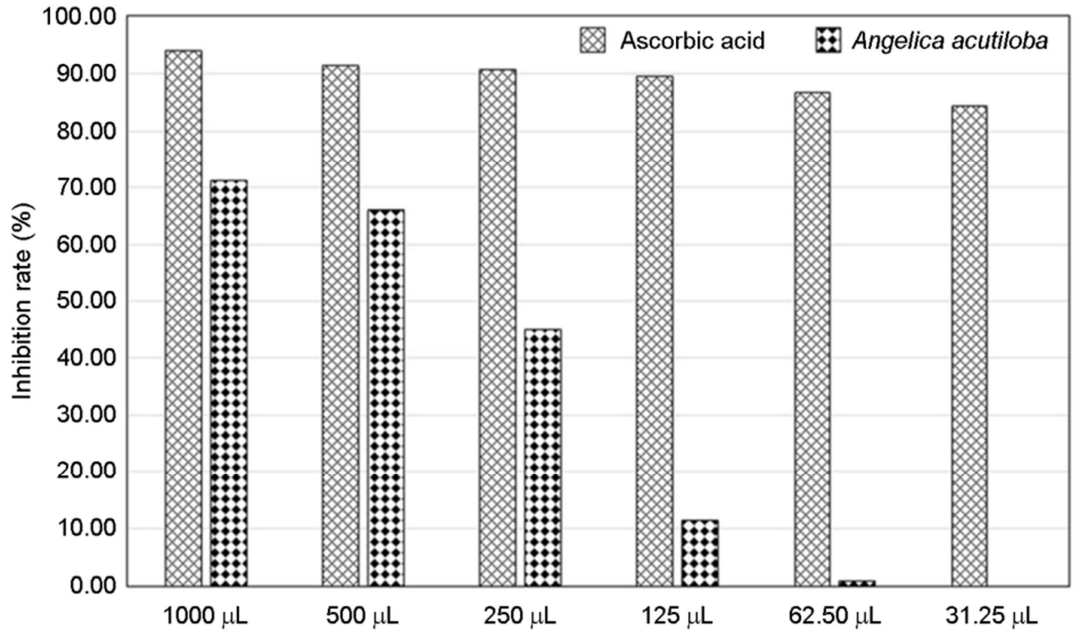

Fig. 3. Antioxidant activity of Angelica acutiloba by $\alpha, \alpha$-diphenyl- $\beta$-picrylhydrazyl (DPPH) test. 1,000 $\mu \mathrm{L}$ of Angelica acutiloba hadantioxidant activity of 71.25 , whereas its $62.50 \mu \mathrm{L}$ had an activity of $0.96 \%$. However, $0 \%$ was in the $31.25 \mu \mathrm{L}$. 
analysis of inducible nitric oxide synthase (iNOS).

\section{Analyses of variables}

Total WBC: Total WBC \& diff-count were measured using Auto Hematology Analyzer (BC-2800 ver., Shenzhen Mindary Bio-Medical Electronics Co., Ltd., Germany).

Liver and renal markers: To assess toxic effects of the Angelica acutiloba extract, serum aspartate aminotransferase (AST), alanine aminotransferase (ALT), blood urea nitrogen (BUN) and uric acid levels were measured by Autohumalyzer 9500.

NO: To assess the degree of tissue damage and inflammation caused by oxidative NO in all groups, serum NO levels were analyzed. The blood drawn from the heart of the experimental animals was measured using centrifuged plasma at 2,500 rpm. After adding $40 \mu \mathrm{L}$ of a $75 \mathrm{mmol} / \mathrm{L}$ ZnSO 4 solution to $10 \mu \mathrm{L}$ of plasma, $50 \mu \mathrm{L}$ of a $55 \mathrm{mmol} / \mathrm{L} \mathrm{NaOH}$ solution was mixed and centrifuged at $16,110 \times \mathrm{G}$ for 10 minutes. Glycine buffer was added to $80 \mu \mathrm{L}$ of the supernatant, Then, nitric oxide was measured after proteolysis.

$100 \mu \mathrm{L}$ of Griess reagent [1\% (w/v) sulfanilamide, $0.1 \%$ $(\mathrm{w} / \mathrm{v})$ naphtylethylenediamine in $2.5 \%(\mathrm{v} / \mathrm{v})$ phosphoric acid] were added to $120 \mu \mathrm{L}$ of the supernatant. The mixture was incubated in 96-well plates for 15 minutes and absorbance was measured at $540 \mathrm{~nm}$ using an ELISA reader. Standard concentration curves were obtained by stepwise dilution of sodium nitrite $\left(\mathrm{NaNO}_{2}\right)$.

Western blot for iNOS: The skin tissues were finely chopped with surgical knife, and homogenized with homogenizer by adding lysis buffer. This was centrifuged at $4{ }^{\circ} \mathrm{C}$ for 10 minutes at 13,000 rpm. The supernatant was added to a commercially available reagent (Bio-Rad Protein assay Kit, Bio-Rad Hurcules, CA, USA) and the protein absorbance at $595 \mathrm{~nm}$ was measured. DW (distilled water) and sample buffer were mixed with the supernatant and an appropriate amount, respectively. After heating at $95^{\circ} \mathrm{C}$ for 10 minutes, the mixture was cooled at $-20^{\circ} \mathrm{C}$ for 3 minutes, and then $18.5 \mu \mathrm{L}$ of sample was loaded on each $10 \sim 12 \%$ sodium dodecyl sulfate-polyacrylamide gel. This was electrophoresed at 70 volts for 30 minutes and at 100 volts for 1 hour and 30 minutes. The electrophoresed proteins were transferred to a nitrocellulose membrane under refrigeration at 100 volts for 1 hour and 30 minutes. Membranes were stained with Ponceau solution, and blocking was performed using a blocking buffer. The primary antibodies iNOS and $\beta$-actin were washed with $0.1 \%$ Tween 20 (PBST) 5 times for 7 minutes after over night at $4{ }^{\circ} \mathrm{C}$. After the secondary $\mathrm{Ab}$ was attached for 2 hours at room temperature, expression and analysis were performed using ECL prime (Amersham Parmacia Biotech, Buckinghamshire, London, UK). The results were quantified using vision works image software and quantified by calibrating the amount of each signal transduction protein with the $\beta$-actin, a house keeping gene. Control protein expression level as 1 was compared and the differences in protein expression levels between groups were compared.

\section{Statistical analysis}

All data were expressed as means \pm standard deviation (SD). The statistical significances among the five groups were identified by ANOVA and then Scheffe post hoc test (SPSS, version 21.0) was applied. $P \leq 0.05$ was accepted to be statistically significant.

\section{RESULTS}

\section{Hematology}

Leukocyte indices: Table 1 compares the changes in leukocyte indices of the five groups. Total leukocyte and granulocyte counts were significantly higher in the vehicle, the low-dose and the high-dose groups than the control group $(P<0.05)$, but the total leukocyte counts in the high-dose group were significantly lower than those in the vehicle group $(P<0.05)$. In the lymphocyte, monocyte and eosinophil counts, the vehicle and low-dose groups were significantly higher than the control group $(P<0.05)$, but the high-dose and antihistamine groups were not significantly different from the control group and were significantly lower than the vehicle group $(P<0.05)$. The $\mathrm{N} / \mathrm{L}$ ratio was the highest in the vehicle group $(P<0.05)$, and the low-dose and the high-dose groups were significantly lower than the vehicle group $(P<0.05)$. 
Table 1. Leukocyte indices in the five groups

\begin{tabular}{|c|c|c|c|c|c|}
\hline Variable $\quad$ Group & Control & Vehicle & Low-dose & High-dose & Antihistamine \\
\hline $\mathrm{T}-\mathrm{WBC}\left(\times 10^{3} / \mu \mathrm{L}\right)$ & $5.39 \pm 1.34$ & $6.37 \pm 1.84^{*}$ & $8.12 \pm 2.40^{*}$ & $6.01 \pm 1.65^{* \dagger}$ & $5.05 \pm 1.38^{\dagger}$ \\
\hline Neutrophil $\left(\times 10^{3} / \mu \mathrm{L}\right)$ & $0.95 \pm 0.21$ & $2.51 \pm 0.67^{*}$ & $2.55 \pm 0.55^{*}$ & $1.51 \pm 0.52^{* \dagger}$ & $1.02 \pm 0.60^{\dagger}$ \\
\hline Lymphocyte $\left(\times 10^{3} / \mu \mathrm{L}\right)$ & $4.23 \pm 1.26$ & $3.58 \pm 1.23^{*}$ & $5.35 \pm 1.57^{*}$ & $4.30 \pm 1.71^{\dagger}$ & $3.90 \pm 1.42^{*}$ \\
\hline Monocyte $\left(\times 10^{3} / \mu \mathrm{L}\right)$ & $0.13 \pm 0.02$ & $0.21 \pm 0.03^{*}$ & $0.25 \pm 0.03^{*}$ & $0.14 \pm 0.01^{\dagger}$ & $0.13 \pm 0.01^{\dagger}$ \\
\hline Eosinophil $\left(\times 10^{3} / \mu \mathrm{L}\right)$ & $0.11 \pm 0.01$ & $0.38 \pm 0.02^{*}$ & $0.49 \pm 0.03^{*}$ & $0.18 \pm 0.01^{\dagger}$ & $0.10 \pm 0.01^{\dagger}$ \\
\hline $\mathrm{N} / \mathrm{L}$ ratio & $0.22 \pm 0.04$ & $0.70 \pm 0.07^{*}$ & $0.47 \pm 0.03^{\dagger}$ & $0.35 \pm 0.03^{\dagger}$ & $0.26 \pm 0.02^{\dagger}$ \\
\hline Neutrophil (\%) & $18.73 \pm 12.31$ & $40.51 \pm 13.54^{*}$ & $31.53 \pm 10.26^{*}$ & $26.36 \pm 9.92^{* \dagger}$ & $21.42 \pm 9.57^{\dagger}$ \\
\hline Lymphocyte (\%) & $78.73 \pm 17.40$ & $55.16 \pm 19.67^{*}$ & $65.07 \pm 16.84^{* \dagger}$ & $70.74 \pm 16.60^{* \dagger}$ & $75.92 \pm 17.05^{*}$ \\
\hline Monocyte (\%) & $2.55 \pm 1.00$ & $4.39 \pm 1.68^{*}$ & $3.41 \pm 1.52^{* \dagger}$ & $2.90 \pm 1.10^{\dagger}$ & $2.68 \pm 1.24^{\dagger}$ \\
\hline Eosinophil (\%) & $0.02 \pm 0.00$ & $0.06 \pm 0.01^{*}$ & $0.06 \pm 0.01$ & $0.03 \pm 0.00^{\dagger}$ & $0.02 \pm 0.00^{\dagger}$ \\
\hline
\end{tabular}

Data are expressed mean \pm standard deviation (SD).

$*, P<0.05$ (statistical significance compared with the control group); $\uparrow, P<0.05$ (statistical significance compared with the vehicle group). Abbreviation: Control, normal rats without atopic dermatitis; vehicle, atopic dermatitis group; Low-dose, atopic dermatitis $+12.5 \mathrm{mg}$ of Angelica acutiloba; High-dose, atopic dermatitis $+50 \mathrm{mg}$ of Angelica acutiloba; Antihistamine, atopic dermatitis + antihistamine-treated group; T-WBC, total white blood cell; N/L ratio, neutrophil/lymphocyte ratio

Table 2. Liver and renal markers in the five groups

\begin{tabular}{|c|c|c|c|c|c|}
\hline Variable $\quad$ Group & Control & Vehicle & Low-dose & High-dose & Antihistamine \\
\hline $\operatorname{AST}(\mathrm{U} / \mathrm{L})$ & $181.82 \pm 28.47$ & $137.40 \pm 32.46$ & $155.25 \pm 34.33$ & $145.86 \pm 31.03$ & $153.81 \pm 36.70$ \\
\hline ALT (U/L) & $27.15 \pm 12.40$ & $28.60 \pm 13.42$ & $25.25 \pm 10.67$ & $27.85 \pm 13.45$ & $28.67 \pm 14.40$ \\
\hline BUN (mg/dL) & $34.42 \pm 10.07$ & $36.21 \pm 11.14$ & $22.85 \pm 7.51^{* \dagger}$ & $16.87 \pm 6.41^{* \dagger}$ & $18.36 \pm 8.48$ \\
\hline $\mathrm{UA}(\mathrm{mg} / \mathrm{dL})$ & $0.51 \pm 0.03$ & $0.42 \pm 0.03$ & $0.36 \pm 0.02$ & $0.40 \pm 0.02$ & $0.42 \pm 0.02$ \\
\hline
\end{tabular}

Data are expressed mean \pm standard deviation (SD).

$*, P<0.05$ (statistical significance compared with the control group); $\uparrow, P<0.05$ (statistical significance compared with the vehicle group).

In comparisons between Angelica acutiloba extract groups, the high-dose group had significantly lower levels of total leukocyte, neutrophil, lymphocyte, monocyte and eosinophil counts and N/R ratio than the low-dose group $(P<0.05)$.

\section{Liver and renal markers}

In both the low- and high-dose groups, Angelica acutiloba extract administered did not show any toxic effects on the liver and kidneys (Table 2).

\section{Serum nitric oxide (NO)}

Serum NO concentrations were the highest in the vehicle group. Serum NO concentrations in the low-, high- and antihistamine groups were significantly lower than those in the vehicle group $(P<0.05)$. In comparisons between Angelica acutiloba extract groups, high-dose group showed a slightly lower trend compared with low-dose group, but no statistical significance $(P>0.05)$ (Fig. 4$)$.

\section{iNOS expression of skin tissues}

The iNOS expression of the skin tissues were the highest in the vehicle group. The iNOS expression levels in the low-, high- and antihistamine groups were significantly lower than those in the vehicle group $(P<0.05)$. In comparisons between Angelica acutiloba extract groups, high-dose group had significantly lower iNOS expression levels than lowdose group $(P<0.05)$ (Fig. 5). 


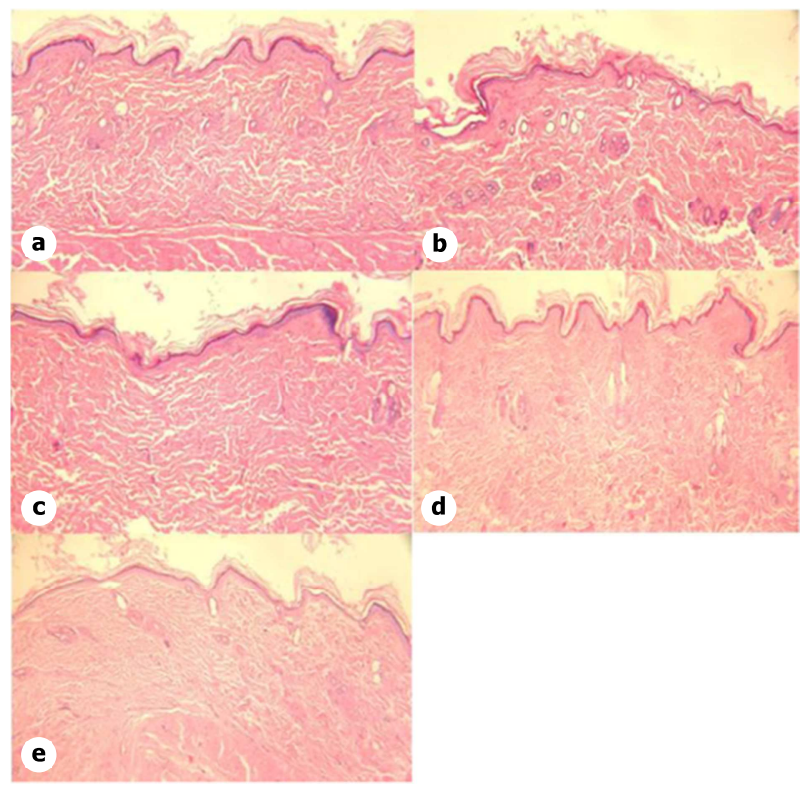

Fig. 5. Histological findings of the skin tissue $(\mathrm{H} \& \mathrm{E}$ stain, magnification $\times 200$ ). a, control group; b, vehicle group (atopic dermatitis); c, low-dose group; d, high-dose group; e, anhistamine group. Excessive epidermal hyperplasia, hyperkeratosis, epidermal parakeratosis, marked leukocyte infiltration in the dermis, and dermal edema were observed on the skin of rat in the atopic dermatitis group (b). The epidermal changes and dermal infiltrations were reduced in the $\mathrm{c}, \mathrm{d}$ and e groups.

\section{DISCUSSION}

Recently, several researchers have also focused on alternative therapies using traditional herbs to overcome the limitations of existing therapies for atopic dermatitis reported that Traditional herb Hyangso-san inhibited TNF- $\alpha$ and IFN$\gamma$-induced STAT1 activation, thereby inhibiting TNF- $\alpha$ and IFN- $\gamma$ mediated chemokine production and expression. In addition (Tao et al., 2017), demonstrated that Calycosin (a bioactive component of Astragali Radix, which is a Chinese herb for treating allergy), attenuated the destruction of epithelial TJs by reducing the secretion of TSLP/IL-33 and inhibiting the TLR4 mediated NF-אB signaling pathways, suggesting that this may be an alternative treatment for atopic dermatitis. In this study, total leukocyte, neutrophil, lymphocyte, monocyte, eosinophil, neutrophil//ymphocyte ratio levels were significantly lower in the high-dose of Angelica acutiloba extract than in the allergic dermatitis group (vehicle group). This means that the Angelica acutiloba extract alleviates the inflammatory reaction which is the cause of allergic dermatitis. In the case of inflammatory diseases including atopic dermatitis, the above-mentioned peripheral blood leukocyte lineage cells as well as the N/L ratio (NLR) are also increased (Dogru and Citli, 2017). Especially, NLR is a novel marker for assessment of inflammation. NLR has the advantages of being readily available, inexpensive and easy to calculate. It is available, cost effective and easy to calculate. NLR is associated with chronic inflammatory diseases such as cardiovascular disease, hypertension and diabetes, and has a prognostic importance (Imtiaz et al., 2012; Biyik et al., 2013; Uslu et al., 2013; Kayadibi et al., 2014; Sahan et al., 2014). Patients with atopic dermatitis have higher NLR (Dogru and Citli, 2017). Patients with atopic dermatitis (AD) exhibit higher neutrophilic inflammation with eosinophilic inflammation (Spergel et al., 1998; Choy et al., 2012; Hon et al., 2013). According to a recent study, AD patients had increased serum IgE levels and blood eosinophil counts related with the score of $\mathrm{AD}$. These studies suggest that neutropenia is a sign of AD. Furthermore (Hon et al., 2013), reported that there was a positive correlation between the severity of $\mathrm{AD}$ and neutrophil count, but a negative correlation with lymphocyte count. The results of the liver and kidney function markers in the low- and high-dose groups of Angelica acutiloba were not significantly different from those of the control group, suggesting that it had no toxic effect. NO is produced in various parts of the body, including the nervous system, lung, liver, gastrointestinal tract, blood vessels, immune system and skin cells (Knowles and Moncada, 1994). NO acts as a messenger molecule in cell-to-cell communication (Lowenstein and Snyder, 1992) and exerts vasodilation, neurotransmission, intestinal peristalsis and other autonomic functions (Biliar, 1995; Moncada and Higgs, 2012). NO is generated by the enzymatic reaction of the nitrogen group with the terminal oxygen of L-arginine with molecular oxygen. NO is also a potent cellular toxin, either protecting the body against invading pathogens and tumor cells or destroying normal cells and tissues (Liew and Cox, 1991). The latter mode of action is of central importance for the role of $\mathrm{NO}$ in host immune defense, immunoregulation, and autoimmune tissue injury (Kolb and Kolb-Bachofen, 1992; Aggård, 1994). Many studies have reported that nitric oxide (NO) correlates with a variety 
of inflammatory diseases. NO causes an inflammatory effect in a dose-dependent manner. In chronic inflammation, a large amount of NO produced by iNOS plays a crucial role. Increased NO concentrations lead to the formation of peroxynitrite, which is in turn harmful both as a result of its direct effect on cellular enzyme-protein systems and through its reaction with superoxide radicals (Sahin et al., 2001). In this study, the serum NO concentration was significantly lower in the low- and high-dose groups than in the vehicle group, indicating the antiinflammatory effect of Angelica acutiloba. iNOS plays an important role in the production of NO. The proper amount of iNOS plays an essential role in the physiology of the human body, but overproduction is involved in the development of a number of inflammatory diseases including cancer (Vannin et al., 2015). In this study, iNOS expression level of skin tissue was significantly lower in Augerica acutiloba groups than that of vehicle. Therefore, the effect of Augerica acutiloba on dermatitis was confirmed. Especially, high-dose group showed lower iNOS expression than low-dose group, meaning that high doses of Augerica acutiloba are more effective in the treatment of atopic dermatitis. In this study, NO/iNOS expression of the skin tissues was the highest in the vehicle group, but the Augerica acutiloba groups were significantly lower, suggesting antiallergic dermatitis effects of Augerica acutiloba.

\section{ACKNOWLEDGEMENT}

None.

\section{CONFLICT OF INTEREST}

No conflicts of interest are involved in this manuscript.

\section{REFERENCES}

Aggård E. Nitric oxide: mediator, murderer, and medicine. Lancet. 1994. 343: 1199-1206.

Biliar TR. Nitric oxide: novel biology with clinical relevance. Ann Surg. 1995. 221: 339-349.

Biyik M, Ucar R, Solak Y. Blood neutrophil-to-lymphocyte ratio independently predicts survival in patients with liver cirrhosis. Eur J Gastroenterol Hepatol. 2013. 25: 435-441.

Choy DF, Hsu DK, Seshasayee D. Comparative transcriptomic analyses of atopic dermatitis and psoriasis reveal shared neutrophilicinflammation. J Allergy Clin Immunol. 2012. 130: 1335 -1343 .

Dogru M, Citli R. The neutrophil-lymphocyte ratio in children with atopic dermatitis: a case-control study. Clin Ter. 2017. 168: 262 -265 .

Fleisher AB Jr. Treatment of atopic dermatitis: Role of tacrolimus ointment as a topical nonsteroidal therapy. J Alleg Clin Immunol. 1999. 104: 126-130.

Haper J, Green A, Scott G, Gruendle E, Dorobek B, Cardno M. First experience of topical SDZ ASM 981 in children with atopic dermatitis. Br J Dermatol. 2001, 144: 781-787.

Holden CA, Parish WE. Atopic dermatitis. In: Champion RH, Burton JL, Burns DA, et al., editors. Textbook of dermatology. 6th ed. Oxford: Blackwell Science. 1998. 6: 681-708.

Hong SJ, Korean ISAAC Study Group of Korean Association of Allergy and Respiratory Diseases. Report of Korean ISAAC epidemiologic study for asthma and allergic diseases in children. Pediatr Allergy Respir Dis. 2007. 17: 55-66.

Hon KL, Wang SS, Pong NH. Circulating immunoglobulins, leucocytes and complements in childhood-onset atopic eczema. Indian J Pediatr. 2013. 80: 128-131.

Imtiaz F, Shafique K, Mirza SS. Neutrophil lymphocyte ratio as a measure of systemic inflammation in prevalent chronic diseases in Asian population. Int Arch Med. 2012. 5: 2.

Kang S, Lucky AW, Praiser D, Lawlence I, Hanifin JM. Long-term safety and efficacy tacrolimus ointment for the treatment of atopic dermatitis in children. J Am Acad Dermatol. 2001. 44: 58-64.

Kayadibi H, Sertoglu E, Uyanik M. Neutrophillymphocyte ratio is useful for the prognosis of patients with hepatocellular carcinoma. World J Gastroenterol. 2014. 20: 9631-9632.

Kim SD, Cho SH. Treatment for atopic dermatitis. J Korean Med Assoc. 2014. 57: 226-233.

Knowles RG, Moncada S. Nitric oxide synthases in mammals. Biochem J. 1994. 298: 249-258.

Kolb H, Kolb-Bachofen V. Nitric oxide: a pathogenic factor in autoimmunity. Immunol Today. 1992. 13: 157-160.

Krakowski AC, Eichenfield LF, Dohil MA. Management of atopic dermatitis in the pediatric population. Pediatrics. 2008. 122: 812-824.

Liew FY, Cox FEG. Nonspecific defense mechanism: the role of nitric oxide. Immunol Today. 1991. 12: 17-21.

Lowenstein CJ, Snyder SH. Nitric oxide, a novel biologic messenger. 
Cell. 1992. 70: 705-707.

Moncada S, Higgs A. The L-arginine-nitric oxide pathway. N Engl J Med. 2012. 329: 2002-2012.

Murphy LA, Atherton DJ. Arzathioprine in severe childhood eczema: value of TPMT as a predictor of outcom and safety in treatment. Br J Dermatol. 2001. 144: 927.

Pawankar R, Bunnag C, Chen Y, Fukuda T, Kim YY, Le LT, Huong le TT, O'Hehir RE, Ohta K, Vichyanond P, Wang DY, Zhong $\mathrm{N}$, Khaltaev N, Bousquet J. Allergic rhinitis and its impact on asthma update (ARIA 2008)-western and Asian-Pacific perspective. Asian Pac J Allergy Immunol. 2009. 27: 237-243.

Sahan E, Polat S. Neutrophil to lymphocyte ratio is associated with more extensive, severe and complex coronary artery disease and impaired myocardial perfusion. Turk Kardiyol Dern Ars. 2014. 42: 415.

Sahin S, Önder M, Sancak B, Bukan N, Gürer MA. The role of nitric oxide in allergic contact dermatitis. Arch Dermatol Res. 2001. 293: 214-217.

Sidbury R, Hanifin JM. Systemic therapy of atopic dermatitis. Cli Exp Dermatol. 2000. 25: 559-566.

Spergel JM, Mizoguchi E, Brewer JP. Epicutaneous sensitization with protein antigen induces localized allergic dermatitis and hyperresponsiveness to methacholine after single exposure to aerosolized antigen in mice. J Clin Invest. 1998. 101: 1614 -1622 .

Tao Y, Wang Y, Wang X, Wang C, Bao K, Ji L, Jiang G, Hong M. Calycosin Suppresses Epithelial Derived Initiative Key Factors and Maintains Epithelial Barrier in Allergic Inflammation via TLR4 Mediated NF-кB Pathway. Cell Physiol Biochem. 2017. 44: 1106-1119.

Uslu AU, Deveci K, Korkmaz S. Is neutrophil/lymphocyte ratio associated with subclinical inflammation and amyloidosis in patients with familial Mediterranean fever? Biomed Res Int. 2013. 185-317.

Vannini F, Kashfi K, Nathb N. The dual role of iNOS in cancer. Redox Biol. 2015. 6: 334-343.

https://doi.org/10.15616/BSL.2019.25.1.83

Cite this article as: Cho MS, Park HW, Lee GH, Yoon HG, Oh KM, Choi SC, Hyun KY. The Ameliorative Effect of Angelica acutiloba Ameliorates Through the NO / iNOS Pathway in Rats with Systemic Allergy. Biomedical Science Letters. 2019. 25: 83-91. 